\title{
Comparing the emerging psychological meaning of tattoos in drug-addicted and not drug-addicted adults: A look inside health risks
}

\author{
Concetta Pirrone, ${ }^{1}$ Sabrina Castellano, ${ }^{1}$ Giuseppe Alessio Platania, ${ }^{1}$ Stefano Ruggieri, ${ }^{2}$ \\ Pasquale Caponnetto ${ }^{1}$ \\ ${ }^{1}$ Department of Educational Sciences, University of Catania, Catania; ${ }^{2}$ Department of Human
and Society Sciences, Kore University, Enna, Italy
}

\begin{abstract}
Although tattoos have been historically characteristic of criminals and drug addicts therefore carrying negative associations, it is now an accepted and appreciated form of body modification. Tattoos could be considered as a projective psychological test, most people use their body as blackboard to represent the most varied meanings related to the way they perceive themselves. It is also true that tattoos can assume the role of diagnostic indicators for a possible abuse of psychoactive substances, as well as their aggregating and communicative functions within the group of drug addicts. The aim of this cross-sectional study was to explore the relation among personality traits, self-efficacy, locus of control and motivations for tattooing. The sample consisted of $150 \mathrm{sub}-$ jects, 50 tattooed adults, 50 tattooed drug addicted adults, and 50 non-tattooed adults. Data were collected by using the Big Five Questionnaire (BFQ), the Perceived Self- efficacy Test, the Mini Locus of Control scale and a Tattoos Inventory. Results of the present study contribute to a deeper understanding of the new meaning of tattoos, they no longer represent personality traits, they rather have the function of reinforcing beliefs about how to perceive oneself, this happens especially in drug addicts in which the
\end{abstract}

Correspondence: Pasquale Caponnetto, Department of Educational Sciences, University of Catania, Palazzo Ingrassia Via Biblioteca, 4, 95124, Catania, Italy.

E-mail: p.caponnetto@unict.it

Key words: Tattoos; Personality; Drugs addicted; Locus of control; Self-efficacy.

Contributions: The authors contributed equally.

Conflict of interest: The authors declare no conflict of interest.

Ethics approval and consent to participate: The study was approved by the Internal Ethics Review Board of the Department of Educational Sciences, Section of Psychology, University of Catania. Participants gave their written consent.

Received for publication: 20 July 2020

Accepted for publication: 20 August 2020.

This work is licensed under a Creative Commons AttributionNonCommercial 4.0 International License (CC BY-NC 4.0).

C Copyright: the Author(s), 2020

Licensee PAGEPress, Italy

Health Psychology Research 2020; 8:9268

doi:10.4081/hpr:2020.9268 presence of tattoos reinforces the illusory belief of self-esteem and internal locus of control. Given the rising presence of tattoos today, this could be useful to get a better understanding of the existential unease of certain populations.

\section{Introduction}

The World Health Organization (WHO) has defined drug addiction as a chronic and physical condition that takes a chronically course, which leads the individual to take different substances at increasing doses, with the aim of experiencing temporarily beneficial effects. The need for this effect becomes intimately linked to the continuous intake of the substance (WHO, 2019). The latest report from the United Nations agency, dating back to 2017, shows a worrying picture: 271 million people have used drugs. In particular, the World Drug Report 2019 reported that $5.5 \%$ of the world population takes drugs. These data are in line with those of 2016, but compared to 2009 there was an increase of $30 \%$ (UNODC, 2019). An accurate review of recent literature (Brooks Woods, Knight, \& Shrier, 2003; Deschesnes, Demers \& Finès, 2006; Stephens, 2003; Suris, Jeannin, Chossis, \& Michaud, 2007) has allowed to verify the existence of a limited number of studies that analysed the correlation between tattooed subjects, and their tendency to adopt risky behaviours such as smoking, alcohol and drug abuse (Drews, Allison \& Probst, 2000; Forbes, 2001 Greif, Hewitt \& Armstrong, 1999;), or engaging in illegal behaviours and activities (Tiggemann \& Hopkins, 2011). Even among adolescents, the tendency to tattoo has been associated with the use of drugs or alcohol (Carrol, Riffenburgh, Roberts, \& Myhre, 2002; Deschesnes, Finès \& Demers, 2006; Roberts \& Ryan, 2002; Silver, VanEseltine \& Silver, 2009). Stirn, Hinz and Brähler (2006), for example, conducted a study in which it emerged that as the age increases, subjects relied on body modifications not only because of a pessimistic view of their existence and reduced ability to interact socialy, but also because of a continuous search for sensation seeking, caused by alcohol and drugs abuse (Stirn, Hinz, \& Brähler, 2006). As has been noted, there are not a variety of researches that analyse tattoos and drug addiction together. This is due to the fact that scholars, over time, have focused more on analysing the correlation between tattoos and deviant behaviour in general (Armstrong, Roberts, Owen, \& Koch, 2004; Koch Roberts, Armstrong, \& Owen, 2010; Mayers, Judelson, Moriarty, \& Rundell, 2002; Swami 2011). The results of the study by D'Ambrosio, Martini and Casillo (2014), confirm what we mentioned above. In fact, they conducted a study on 121 tattooed and non-tattooed subjects, with the aim of evaluating their psychological and personological profiles related to these practices. It is true that bodily changes are now customs rooted in modern western societies having a primarily aesthetic purpose, but 
it is also true that they can constitute a sign of uneasiness or inner malaise that the subject can hardly communicate in a different way (D'Ambrosio, Martini \& Casillo, 2014). A much more recent study (Ceylan, Hesapcioglu, Kasak, \& Yavas, 2019) also confirmed the correctness of this perspective, the authors investigated the association of psychiatric illnesses (conduct disorder, depression, substance abuse, post-traumatic stress disorder, psychotic disorder and specific attention disorder) between detained and non-detained minors, and the number of tattoos possessed; the data reported not only an increase in all psychiatric illnesses in adolescent prisoners, but also a significantly higher number of tattoos in the latter, which in turn is also associated with an increase in criminal behaviour. A particular stereotype attributed to those who aroused to tattoo concerns pathological aggression; in fact, many authors have argued that tattooed subjects tend to be more aggressive and rebellious than those who do not tattoo (Totten, Lipscomb, \& Jones, 2009). Various researches on Serbian adolescents (Krasic, Mitic, Kostic, Ilic, \& Rankovic, 2011) and on the island of Taiwan (Yen et al., 2012) have also shown, in tattooed subjects, higher levels of selfreported aggression and a greater probability of violence compared to non-tattooed subjects.

Moreover, in the past, tattooed subjects were considered individuals belonging to external groups or marginalized by society, such as motorcyclists and prisoners, stereotypically represented as aggressive; in fact, several authors (Hawkins \& Popplestone, 1964) have compared the tendency to get tattooed with the socalled "exoskeletal" defence, a symbol of physical prowess and aggression. In the contemporary era, however, it is possible to state that the tattoo no longer represents an instrument of social categorization, through which stereotypically include a subject within a specific deviant group. On the contrary, the tattoo has now become a fashion, and it is used by all people as a tool to express their personality and define their self-esteem (Antoszewski, Sitek, Fijałkowska, Kasielska, \& Kruk-Jeromin, 2010; Stirn, 2003; Wohlrab, Stahl \& Kappeler, 2007;). In the light of this, it is no longer interesting to analyse the tattooed subjects in terms of deviance, with the aim of being able to understand the peculiar features of their behaviour, but to study the latter in terms of "normality". For this reason, the constructs we used in this research concern both self-efficacy and the Locus of Control (LOC). In particular, self-efficacy has been described by Bandura (1994) as "the belief that people have to be able to implement behaviours that will produce a desired result". It represents, together with the internal LOC, a proper construct to those individuals who flaunt security and determination. Given this, and also taking into account the previous literature that states that drug addicts use substances to feel more in control of themselves, our goal becomes to investigate whether tattoos continue to differentiate the population in terms of deviant or normal behaviour.

\section{Materials and Methods}

\section{Design}

A cross-sectional design was employed.

\section{Study population}

The sample of the study consisted of 150 subjects divided according to whether they have tattoos and if they are drugs addicted. Thus, 50 are young Non-Tattooed Adults (NoTA) (first group); 50 are young Tattooed Adults (TNA) (second group); and 50 are young Tattooed Drug Addicts Adults (TADA) (third group). For our first TNA group, data collection was performed in a tattoo shop, where we asked the owner and the clients to answer to some tests in order to investigate the "phenomenon" of tattooing. For our second NoTA group, data collection was collected in a different Department of Catania University. For our third TADA group, data collection was performed at Catania Hospital (SER.T services for drug addicts); these subjects were all in pharmacological outpatient drug treatment; although the right to privacy and anonymity was guaranteed, we encountered several difficulties in recruiting the sample of tattooed drug addicts as they were inconsistent, little persevering and suspicious, a typical characteristics of the addict profile but, despite these hurdles, we achieved in our aim, lead the sample to complete all tests.

\section{Ethical considerations}

Our subjects, who met the entry criteria were informed by the researchers regarding the purposes of the study and participated only after they had given their written consent. All of them participated in the study on a voluntary basis and had their anonymity preserved. Participants were informed that their participation was voluntary and that they could withdraw at any time, according to the ethical standards of the Helsinki Declaration of 1983. The study was approved by the Internal Ethics Review Board of the Department of Educational Sciences, Section of Psychology, University of Catania.

\section{Measures}

The Big Five Questionnaire (BFQ; Caprara, Barbaranelli, \& Borgogni, 1993) is composed of 132 items assessing the five major trait personality factors using a 5-point Likert-type scale. The Cronbach alpha values reported by the authors are: 0.84 for extraversion, 0.73 for agreeableness, 0.81 for conscientiousness; 0.90 for emotional stability; and 0.75 for openness.

Self-efficacy was investigated using the Perceived Self- efficacy Test (Schwarzer, 1993), a self-report instrument composed of 10 items rated on a four-point Likert scale, covering the degree of belief that one is capable of performing in a certain manner to obtain certain goals. The scale presents a good reliability (Cronbach's alpha ranges are from 0.75 to 0.94 ). LOC was investigated through the Italian version of the Mini Locus of Control scale (Perussia \& Viano, 2008), a self-report structure based on 3 factors composed of 6 items rated on a four-point Likert scale. Chance is related to destiny or fate (results are predetermined and individuals perceive themselves to have little or no control over their achievement), Powerful of others represents the influences applied from social context, and Internality is related to the will, the personal capabilities, and measures internal locus of control. The sum of the above gives us a new factor named "Total LOC" that measures external locus of control (Cascio, Botta \& Anzaldi, 2013 , p. 9). Psychometric index of validity and reliability are available at www.itapi.org, the web site directly managed by the Authors.

Finally, the Questionnaire on the characteristics and motivations of the tattoo was administered to the tattooed subjects of the sample, in order to detect the quantitative and qualitative aspects of the tattoo. They were, number of tattoos; age of the first tattoo; visibility of the tattoo (dimensions: small and/or medium and/or large, and part of the body tattooed); regret getting tattoos; tattoos body position (head, arms, feet, etc.); type of tattoo (realistic, Maori, Japanese, tribal, others). Regarding the motivations, the items chosen were the following: I like tattoos; It is fashionable; 
Transgressions; Have a memento; to show a side of my personality; to look more like famous people; to be accepted by a group; to be accepted by my peers; because I like to conform.

\section{Data analysis}

Percentages, means, and standard deviations were calculated in order to provide a broader view of the data. Results were reported primarily for the whole sample and secondarily for each of the subgroups except the no tattooed group. All data exhibited normal distribution and thus the parametric t-test and ANOVA were used as well as cross tabulations with $\chi 2$ test for categorical variables. For the two groups, TNA and TADA, Pearson's correlation coefficient was used to identify the relationship between the studied variables; in this case, for practical reasons, we reported only statistically significant results. To assess the moderate role of tattoo visibility and tattoo repentance, the interaction term was calculated between TADA and TNA status and self-efficacy. Results indicated differences with a probability of less than or equal to 0.05 and were accepted as significant. For statistical analysis, we used the statistical program (SPSS v. 25, Chicago, IL, USA).

\section{Results}

Concerning NoTA group, $25(50 \%)$ are men, 25 (50\%) are women, age ranged from 18 to 30 years old with a mean of 24.70 \pm 3.30 . As for the qualification, 7 (14\%) subjects have lower secondary education, $18(36 \%)$ subjects have high school diploma, $25(50 \%)$ subjects have a degree.

Regarding TNA group, 25 (50\%) are men, 25 (50\%) are women, age ranged from 18 to 30 years old with a mean of $24.86 \pm 3.30$. As for the qualification, our subjects $11(22 \%)$ subjects have lower secondary education, 17 (34\%) subjects have high school diploma, 22 (44\%) subjects have a degree. In regard to the number of tattoos, our subjects have a mean of 2,20 (SD 1,61). Regarding the first tattoo age, $13(26 \%)$ subject did it under the age of $18,31(62 \%)$ subjects did it from 18 to 25 years old, $6(12 \%)$ subjects did it from 26 to 33 years old.

Concerning TADA group, 45 are men $(90 \%), 5$ (10\%) are women, age ranged from 19 to 54 years old with a mean of $35.40 \pm 8.33$. As for the qualification of our subjects, $30(60 \%)$ have lower secondary education, 14 (28\%) have high school diploma, 2 $(4 \%)$ have a degree, and $8(8 \%)$ have other titles. Relating to number's tattoo, our subjects have a mean of 4,14 (SD 2,20). Regarding the first tattoo age, 22 (44\%) subjects did it under the age of 18, 22 (44\%) subjects did it from 18 to 25 years old, 6 (12\%) subjects did it from 26 to 33 years old. Other tattoos characteristics are presented in Table 1.

In order to assess statistical significance among the three groups at the Big Five Personality Traits, we carried out one-way ANOVA. NoTA are significantly more Conscientious [F (3.856), $\mathrm{p}=0.023]$ than TNA e TADA. Regarding Self Efficacy, to our surprise, TADA showed a significantly higher score than TNA and NoTA [F (67.45), $\mathrm{p}=0.000]$. Additionally, whit regard to LOC and its sub-scales, NoTA result more externalist than TNA and TADA [F (4.147), $\mathrm{p}=0.018]$ and, the latter is least externalist of all.

To evaluate tattoo dimensions we compared only TDA e TADA groups, excluding NoTA because of they haven't got any tattoo. Chi-square test showed that TADA prefer realistic and Maori tattoos more than TNA $\mathrm{X}^{2}(4, \mathrm{~N}=100)=16.604, \mathrm{p}=0.002$. Regarding the three dimensions of tattoo, small, medium and large, TADA have got larger and medium tattoos more than TNA who prefer small tattoos $X^{2}(2, N=100)=29.731, p=0.000$. Regarding tattoo body position, TADA prefer back and chest, TNA prefer harms, legs and feet $\mathrm{X}^{2}(3, \mathrm{~N}=100)=8.451, \mathrm{p}=0.003$.

To gain a better view of our sample, we proceeded with the Pearson's correlations by type: TNA and TADA.

Regarding TNA group, as shown on Table 2, number of tattoos correlates positively with Fatalism, negatively with Emotional

Table 1. Descriptive statistics of tattooed characteristics sample $(n=100)$.

\begin{tabular}{|c|c|c|c|c|c|}
\hline \multirow[t]{2}{*}{ Tattoo } & \multirow[b]{2}{*}{ f } & \multicolumn{2}{|c|}{ TNA } & \multicolumn{2}{|c|}{ TADA } \\
\hline & & $\%$ & f & $\%$ & \\
\hline Dimension & $\begin{array}{l}\text { Small } \\
\text { Medium } \\
\text { Large }\end{array}$ & $\begin{array}{c}35 \\
15 \\
0\end{array}$ & $\begin{array}{c}70,0 \\
30,0 \\
0,0\end{array}$ & $\begin{array}{c}9 \\
34 \\
7\end{array}$ & $\begin{array}{l}18,0 \\
68,0 \\
14,4\end{array}$ \\
\hline Motivation & $\begin{array}{l}\text { I like tattoos } \\
\text { It is fashionable } \\
\text { Transgression } \\
\text { Have a memento } \\
\text { Personality exhibition }\end{array}$ & $\begin{array}{c}30 \\
4 \\
2 \\
11 \\
3\end{array}$ & $\begin{array}{c}60,0 \\
8,0 \\
4,0 \\
22,0 \\
6,0 \\
\end{array}$ & $\begin{array}{c}24 \\
1 \\
7 \\
8 \\
7\end{array}$ & $\begin{array}{c}48,0 \\
2,0 \\
14,0 \\
16,0 \\
14,0\end{array}$ \\
\hline Type & $\begin{array}{l}\text { Realistic } \\
\text { Maori/Japanese } \\
\text { Tribal } \\
\text { Other } \\
\text { I don't know }\end{array}$ & $\begin{array}{c}22 \\
0 \\
10 \\
11 \\
7\end{array}$ & $\begin{array}{c}44,0 \\
20,0 \\
0 \\
22,0 \\
14,0\end{array}$ & $\begin{array}{c}27 \\
9 \\
7 \\
2 \\
5\end{array}$ & $\begin{array}{c}54,0 \\
18,0 \\
14,0 \\
4,0 \\
10,0\end{array}$ \\
\hline Position & $\begin{array}{l}\text { Head / shoulders } \\
\text { Arms } \\
\text { Back / chest } \\
\text { Legs / feet }\end{array}$ & $\begin{array}{c}12 \\
21 \\
7 \\
10\end{array}$ & $\begin{array}{l}24,0 \\
42,0 \\
14,0 \\
20,0\end{array}$ & $\begin{array}{r}13 \\
15 \\
18 \\
4\end{array}$ & $\begin{array}{c}26,0 \\
30,0 \\
36,0 \\
8,0\end{array}$ \\
\hline Visibility & $\begin{array}{l}\text { Yes important } \\
\text { Not important } \\
\text { Indifferent }\end{array}$ & $\begin{array}{c}5 \\
23 \\
22\end{array}$ & $\begin{array}{l}10,0 \\
46,0 \\
44,0\end{array}$ & $\begin{array}{c}9 \\
20 \\
21\end{array}$ & $\begin{array}{l}18,0 \\
40,0 \\
42,0\end{array}$ \\
\hline One more & Yes & 28 & 56,0 & 32 & 64,0 \\
\hline
\end{tabular}


Stability and Externalism; tattoo first age correlates negatively with Conscientiousness and Mental Openness, positively with dimension of tattoo that in turn correlates negatively with Conscientiousness.

Regarding TADA group, as shown on Table 3, number of tattoos correlates positively with dimension of tattoo, negatively with tattoo first age and, the latter correlates negatively with Conscientiousness. Self-efficacy correlates positively with Energy and Conscientiousness, negatively with Externalist, which in turn correlates negatively with Energy and Conscientiousness.

The interaction effect of tattoo addiction status (TADA/TNA) and tattoo visibility on self-efficacy was significant F (3.444), $p=0.03$. The analysis of variance for the different groups showed that the highest score on self-efficacy was reported by TADA $(\mathrm{m}=42.43 ; \mathrm{ds}=4.8)$ who remain indifferent about the tattoo visibility, while the lowest score was reported by TNA $(m=30.14$; $\mathrm{ds}=6.67$ ), (Figure 1). Similarly, the interaction effect on self- efficacy between tattoo addiction status (TADA/TNA) and regretting

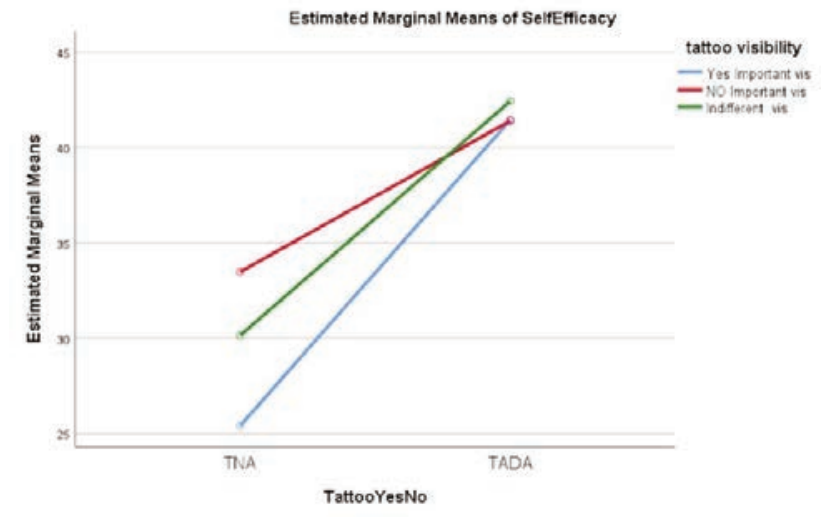

Figure 1. Interaction of tattoo visibility and tattooed addiction status on self- efficacy.

Table 2. TNA group: tattoo self efficacy, LOC and personality traits pearson's correlation.

\begin{tabular}{|c|c|c|c|c|c|c|c|c|}
\hline & 1 & 2 & 3 & 4 & 5 & 6 & 7 & 8 \\
\hline 1 Tatoo $\mathrm{N}^{\circ}$ & 1 & & & & & & & \\
\hline 2 Age Tattoo & $\begin{array}{c}-0.242 \\
0.091\end{array}$ & 1 & & & & & & \\
\hline 3 Tatto Dimens & $\begin{array}{c}-0.136 \\
0.345\end{array}$ & $\begin{array}{c}0.298 * \\
0.036\end{array}$ & 1 & & & & & \\
\hline 4 Fatalism & $\begin{array}{c}0.296^{*} \\
0.037\end{array}$ & $\begin{array}{c}-0.065 \\
0.653\end{array}$ & $\begin{array}{c}-0.160 \\
0.266\end{array}$ & 1 & & & & \\
\hline 5 External & $\begin{array}{c}-0.299 * \\
0.035\end{array}$ & $\begin{array}{l}0.129 \\
0.371\end{array}$ & $\begin{array}{c}-0.022 \\
0.881\end{array}$ & $\begin{array}{r}-0.027 \\
0.855\end{array}$ & 1 & & & \\
\hline 6 Emot Stab & $\begin{array}{c}-0.339 * \\
0.016\end{array}$ & $\begin{array}{l}0.120 \\
0.405\end{array}$ & $\begin{array}{l}0.141 \\
0.327\end{array}$ & $\begin{array}{c}-0.198 \\
0.168\end{array}$ & $\begin{array}{l}0.220 \\
0.124\end{array}$ & 1 & & \\
\hline 7 Conscient & $\begin{array}{l}0.022 \\
0.879\end{array}$ & $\begin{array}{c}-0.279 * \\
0.050\end{array}$ & $\begin{array}{c}-0.364^{* *} \\
0.009\end{array}$ & $\begin{array}{c}-0.093 \\
0.523\end{array}$ & $\begin{array}{c}-0.060 \\
0.678\end{array}$ & $\begin{array}{l}0.048 \\
0.738\end{array}$ & 1 & \\
\hline 8 Open-mind & $\begin{array}{c}-0.016 \\
0.913\end{array}$ & $\begin{array}{c}-0.313^{*} \\
0.027\end{array}$ & $\begin{array}{c}-0.226 \\
0.114\end{array}$ & $\begin{array}{c}-0.028 \\
0.845\end{array}$ & $\begin{array}{l}0.133 \\
0.357\end{array}$ & $\begin{array}{c}-0.112 \\
0.438\end{array}$ & $\begin{array}{c}0.446^{* *} \\
0.001\end{array}$ & 1 \\
\hline
\end{tabular}

${ }^{*} \mathrm{p}<0.05,{ }^{* *} \mathrm{p}<0.01,{ }^{* * *} \mathrm{p}<0.001$

Table 3. TADA Group: tattoo self efficacy, LOC and personality traits pearson's correlation.

\begin{tabular}{|c|c|c|c|c|c|c|c|}
\hline & 1 & 2 & 3 & 4 & 5 & 6 & 7 \\
\hline 1 Tatoo $\mathrm{N}^{\circ}$ & 1 & & & & & & \\
\hline 2 Age Tattoo & $\begin{array}{c}-0.326^{*} \\
0.021\end{array}$ & 1 & & & & & \\
\hline 3 Tatto Dimens & $\begin{array}{c}-0.313^{*} \\
0.027\end{array}$ & $\begin{array}{l}0.068 \\
0.638\end{array}$ & 1 & & & & \\
\hline 4 Self Efficacy & $\begin{array}{c}-0.192 \\
0.181\end{array}$ & $\begin{array}{l}0.015 \\
0.916\end{array}$ & $\begin{array}{l}0.256 \\
0.073\end{array}$ & 1 & & & \\
\hline 5 External & $\begin{array}{c}-0.050 \\
0.731\end{array}$ & $\begin{array}{c}-0.127 \\
0.378\end{array}$ & $\begin{array}{l}0.028 \\
0.846\end{array}$ & $\begin{array}{c}-0.281^{*} \\
0.048\end{array}$ & 1 & & \\
\hline 6 Energy & $\begin{array}{c}-0.157 \\
0.278\end{array}$ & $\begin{array}{r}-0.100 \\
0.490\end{array}$ & $\begin{array}{r}-0.247 \\
0.084\end{array}$ & $\begin{array}{c}0.312^{*} \\
0.028\end{array}$ & $\begin{array}{c}-0.312^{*} \\
0.027\end{array}$ & 1 & \\
\hline 7 Conscient & $\begin{array}{l}0.068 \\
0.638\end{array}$ & $\begin{array}{c}-0.349^{*} \\
0.013\end{array}$ & $\begin{array}{c}-0.056 \\
0.698\end{array}$ & $\begin{array}{c}0.312^{*} \\
0.027\end{array}$ & $\begin{array}{c}-0.193 \\
0.178\end{array}$ & $\begin{array}{c}0.480 * * \\
0.000\end{array}$ & 1 \\
\hline
\end{tabular}

${ }^{*} \mathrm{p}<0.05,{ }^{* *} \mathrm{p}<0.01,{ }^{* * *} \mathrm{p}<0.001$ 
tattoo was significant $F(4,313)=p=0.04$. The highest score on self-efficacy was reported by TADA $(\mathrm{m}=42.41$; $\mathrm{ds}=4.60)$, who don't regret having tattoos; while the lowest score was reported by TNA $(\mathrm{m}=30.98$; ds=6.43), (Figure 2).

\section{Discussion and Conclusions}

The aim of this work was to investigate the meaning that tattoos assume today and its relationship with personality traits, selfeffectiveness and the locus of control in three different populations, tattooed adults with drug addictions (TADA), tattooed adults (TNA), and adults without tattoos (NoTA).

As widely highlighted in the literature, nowadays tattooing is no longer a way to represent and identify deviant behaviours and deviant individuals. Tattoos have changed meaning, representing identity components, pieces of a mosaic that make up the construction of one's own self and of one's own individuality.

Tattooing is becoming more and more popular among the different social and cultural groups, so it seemed interesting to understand the constructs related to the being and feelings of the subjects who choose to tattoo themselves.

Descriptive data shows that TADA prefer larger tattoos, begin tattooing at a very young age and possess more tattoos than NoTA.

The tattoos chosen by our population are predominantly Maori, Japanese and tribal, positioned especially on the back, chest, arms, legs and feet, moreover, none of them are repentant to have gotten a tattoo and rather plan to make more.

The only data that has emerged with regard to personality is that the NoTA are the most conscientious of all, confirming, only in part, what was reported by Nathanson, Paulhus, \& Williams (2006) in a review of the literature on personality traits in tattooed subjects in the absence of pathologies. The authors highlight a close correlation between low conscientiousness, extroversion, psychopathy and body art. Their key aspects are the trait of sensation seeking and impulsivity, both components of psychopathy that is an impulsive search for strong emotions and indifference towards the consequences of their actions that, should increase the probability of getting tattoos, since from the point of view of psychopathic subjects even the markers on the skin are used to push forward the image of the bad/tough boy/girl. The ANOVA and the

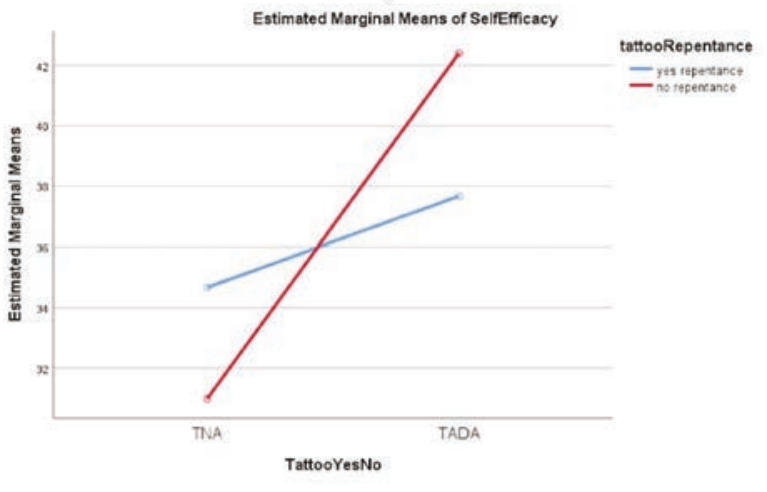

Figure 2. Interaction of tattoo repentance and tattooed addiction status on self- efficacy. correlations have highlighted one of the most interesting result that we did not expect, the TADA have a greater sense of self-efficacy and a lower external LOC than the others, and also these two constructs in the TADA are related to each other. These results contradict what Jetten, Branscombe, Schmitt, \& Spears, (2001) said about the presence of a close correlation between low self-esteem, low self-efficacy, external locus of control and propensity to tattoo. It seems that the subjects with these personality traits live the bodily manipulations as a sort of "ironic self-humiliation" strategy, that is, they willingly accept the social stigma in exchange for friendships with other similar. In our opinion, this development is explained by the psychodynamic approach to drug addiction, according to which the drug addict, as a subject who does not proceed with a correct individuation process capable of alleviating the very first feeling of inferiority, blaming all its failures on the social context, starts from an external locus of control, that is from a mental attitude that gives him in the conviction of not being able to exert any influence on the things and/or situations that occur in his life. Unlike any other (NoTA) subject who shares his attitude, however, the drug addict uses the drug as the only agent capable of fostering an illusion of significance and omnipotence (Adler, 1920), a condition that encourages an increase in self-efficacy, with a consequent predisposition to an illusory locus of internal control. The TNA prefer small, tribal tattoos, placed in the legs/feet and arms areas. TADA prefer medium/large Maori or Japanese tattoos placed in the area of the back/chest. In TADA this choice is not random because it reflects the research and the need to define their identity and belonging. As reported in the literature by Castellani (2005), for the Maori the moko was a very strong sign of individual and social identity, while in Japan, in addition to young people and criminals, there are numerous groups that use the tattoo as a sign of identification or belonging. Another important aspect highlighted by the factorial ANOVA in regard to tattoos, its visibility and the regret of having had it done in the past, the TADA who do not regret having been tattooed and are disinterested about their visibility perceive a greater self-efficacy than TNA. This further data confirms how much, the possession of tattoos is internalized by our subjects, is perceived as a part of the self, gives strength and strengthens the self-efficacy in these subjects.

Ultimately, our study has highlighted that tattooing, rather than being related to personality traits, has the function of adding something to the way of perceiving oneself inwardly, a piece of a mosaic that completes aspects of one's self, so there is no repentance and it doesn't matter whether it is visible or not. The tattoo has to do with the inner world of the still incomplete subject, which in drug addicts is even more fragmentary, ending with the offer of the illusory belief of self-efficacy of a solid internal LOC. This explains how, to make up for their own fragility, TADA have started tattooing very young, have more tattoos and want to do more; the tattoo therefore becomes an external way to complete an internal world still shapeless.

One of the main strength of our research was to succeed in obtaining a sample of 50 TADA who answered all the tests allowing us to have a certain view of the meaning of tattoos. Our study has limitations as well. For example, with the TADA sample, it was complicated to collect more demographic information, they were very reserved and the hospital didn't provide us with further information on their type of addiction. Moreover, it wasn't possible to pair the male and female sample, so we couldn't proceed to detect gender differences, an important information for our research. In the future it would be interesting to be able to fill these gaps. 


\section{References}

Adler, A. (1920). Praxis und Teorie der Individualpsychologie [The practice and theory of individual psychology]. Wiesbaden, Germany: Verlag von JF Bergmann.

Antoszewski, B., Sitek, A., Fijałkowska, M., Kasielska, A., \& Kruk-Jeromin, J. (2010). Tattooing and body piercing-what motivates you to do it? International Journal of Social Psychiatry, 56(5), 471-479.

Armstrong, M. L., Roberts, A. E., Owen, D. C., \& Koch, J. R. (2004). Toward building a composite of college student influences with body art. Issues in Comprehensive Pediatric Nursing, 27(4), 277-295.

Bandura, A. (1994). Self-efficacy. In: Encyclopedia of human behavior, 4, 71-81.

Brooks, T. L., Woods, E. R., Knight, J. R., \& Shrier, L. A. (2003). Body modification and substance use in adolescents: is there a link? Journal of Adolescent Health, 32(1), 44-49.

Caprara, G. V., Barbaranelli, C., Borgogni, L., \& Perugini, M. (1993). The "Big Five Questionnaire": A new questionnaire to assess the five factor model. Personality and individual Differences, 15(3), 281-288.

Carroll, S. T., Riffenburgh, R. H., Roberts, T. A., \& Myhre, E. B. (2002). Tattoos and body piercings as indicators of adolescent risk-taking behaviors. Pediatrics, 109(6), 1021-1027.

Cascio, M., Botta, V., \& Anzaldi, V. (2013). The role of self-efficacy and internal locus of control in online learning. Journal of e-learning and Knowledge Society, 9(3).

Castellani, A. (2005). Le estetiche dei ribelli per la pelle: storia e cultura dei tatuaggi. Costa \& Nolan.

Ceylan, M. F., Hesapcioglu, S. T., Kasak, M., \& Yavas, C. P. (2019). High prevalence of nonsuicidal self-injury, tattoos, and psychiatric comorbidity among male adolescent prisoners and their sociodemographic characteristics. Asian journal of psychiatry, 43, 45-49.

D’Ambrosio, A., Martini, V., \& Casillo, N. (2014). Aspetti psicopatologici dei piercing e dei tatuaggi. Giornale $d i$ Neuropsichiatria dell'Età Evolutiva, 34, 1-10.

Deschesnes, M., Demers, S., \& Finès, P. (2006). Prevalence and characteristics of body piercing and tattooing among high school students. Canadian Journal of Public Health, 97(4), 325-329.

Deschesnes, M., Finès, P., \& Demers, S. (2006). Are tattooing and body piercing indicators of risk-taking behaviours among high school students? Journal of adolescence, 29(3), 379-393.

Drews, D. R., Allison, C. K., \& Probst, J. R. (2000). Behavioral and self-concept differences in tattooed and nontattooed college students. Psychological Reports, 86(2), 475-481.

Forbes, G. B. (2001). College students with tattoos and piercings: Motives, family experiences, personality factors, and perception by others. Psychological reports, 89(3), 774-786.

Greif, J., Hewitt, W., \& Armstrong, M. L. (1999). Tattooing and body piercing: Body art practices among college students. Clinical Nursing Research, 8(4), 368-385.

Hawkins, R. E., \& Popplestone, J. A. (1964). The tattoo as an exoskeletal defense. Perceptual and motor skills, 19(2), 500500 .

Jetten, J., Branscombe, N. R., Schmitt, M. T., \& Spears, R. (2001). Rebels with a cause: Group identification as a response to perceived discrimination from the mainstream. Personality and Social Psychology Bulletin, 27(9), 1204-1213.
Koch, J. R., Roberts, A. E., Armstrong, M. L., \& Owen, D. C. (2010). Body art, deviance, and American college students. The Social Science Journal, 47(1), 151-161.

Krasic, D. B., Mitic, M. L., Kostic, J. S., Ilic, N. M., \& Rankovic, M. Z. (2011). The psychological profile of young people and tattoo changes. European Psychiatry, 26(S2), 315-315.

Mayers, L. B., Judelson, D. A., Moriarty, B. W., \& Rundell, K. W. (2002, January). Prevalence of body art (body piercing and tattooing) in university undergraduates and incidence of medical complications. Mayo Clinic Proceedings 77(1), pp. 29-34.

Nathanson, C., Paulhus, D. L., \& Williams, K. M. (2006). Personality and misconduct correlates of body modification and other cultural deviance markers. Journal of Research in Personality, 40(5), 779-802.

Perussia, F., e Viano, R. (2008). Mini Locus of Control Scale. Piccolo manuale, con Tratti e Tipi, da una Scala psicometrica semplificata. In: Di Nuovo, S., \& Sprini, G. (eds.) Teorie e metodi della psicologia italiana. Tendenze attuali. Milano: Franco Angeli.

Roberts, T. A., \& Ryan, S. A. (2002). Tattooing and high-risk behavior in adolescents. Pediatrics, 110(6), 1058-1063.

Schwarzer, R. (1993). Measurement of perceived self-efficacy. Psychometric scales for cross-cultural research. Berlin: Freie Universitat Berlin.

Silver, E., VanEseltine, M., \& Silver, S. J. (2009). Tattoo acquisition: A prospective longitudinal study of adolescents. Deviant Behavior, 30(6), 511-538.

Stephens, M. B. (2003). Behavioral risks associated with tattooing. Family Medicine-Kansas City, 35(1), 52-54.

Stirn, A. (2003). Body piercing: medical consequences and psychological motivations. The Lancet, 361(9364), 1205-1215.

Stirn, A., Hinz, A., \& Brähler, E. (2006). Prevalence of tattooing and body piercing in Germany and perception of health, mental disorders, and sensation seeking among tattooed and bodypierced individuals. Journal of psychosomatic research, 60(5), 531-534.

Suris, J. C., Jeannin, A., Chossis, I., \& Michaud, P. A. (2007). Piercing among adolescents: Body art as risk marker: A population-based survey. Journal of family practice, 56(2), 126131.

Swami, V. (2011). Marked for life? A prospective study of tattoos on appearance anxiety and dissatisfaction, perceptions of uniqueness, and self-esteem. Body Image, 8(3), 237-244.

Tiggemann, M., \& Hopkins, L. A. (2011). Tattoos and piercings: bodily expressions of uniqueness? Body Image, 8(3), 245-250.

Totten, J. W., Lipscomb, T. J., \& Jones, M. A. (2009). Attitudes toward and stereotypes of persons with body art: Implications for marketing management. Academy of Marketing Studies Journal, 13(2), 77.

United Nations Office on Drugs and Crime (2019). World Drug Report 2019. Available from: https://wdr.unodc.org/wdr2019/

Wohlrab, S., Stahl, J., \& Kappeler, P. M. (2007). Modifying the body: Motivations for getting tattooed and pierced. Body image, 4(1), 87-95.

World Health Organization (2019). Forum on alcohol, drugs and addictive behaviours. Available from: https:/www.who.int/ substance abuse/activities/fadab/2019/en/.

Yen, C. F., Hsiao, R. C., Yen, J. Y., Yeh, Y. C., Wang, P. W., Lin, H. C., \& Ko, C. H. (2012). Tattooing among high school students in southern Taiwan: the prevalence, correlates and associations with risk-taking behaviors and depression. The Kaohsiung journal of medical sciences, 28(7), 383-389. 